\title{
Shape Memory and Superelasticity 2016 Best Paper Award
}

(c) ASM International 2017

Shape Memory and Superelasticity is pleased to announce that "Critical Stresses for Twinning, Slip, and Transformation in Ti-Based Shape Memory Alloys" by Mr. Avinesh Ojha and Dr. Huseyin Sehitoglu is the winner of the 2016 Best Paper Award, as chosen by the journal's Associate Editors. The award will be presented to the winning authors at the International Conference on Shape Memory and Superelastic Technologies (SMST) which will be held May 15-19, 2017 in beautiful Paradise Point in San Diego, California, USA.

The Shape Memory and Superelasticity Best Paper Award in addition to the recognition, includes a plaque and $\$ 1000$ worth of ASM International products and services.

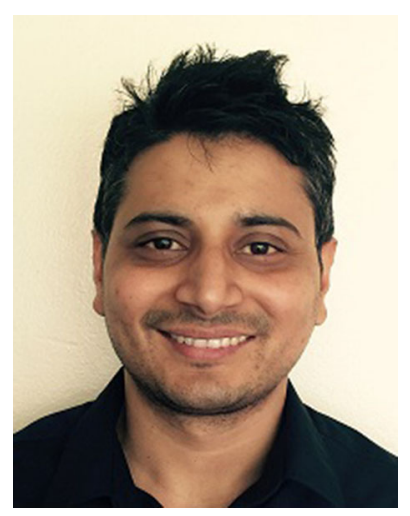

Mr. Avinesh Ojha, University of Illinois at Urbana-Champaign
The Associate Editors of the journal believe it is important to evaluate the quality contributions published in Shape Memory and Superelasticity and to provide recognition of excellent work and its publication. Each paper is reviewed and evaluated on its merits for scientific and engineering content, originality, and presentation style.

To access the article for free go to https://link.springer. com/article/10.1007/s40830-016-0061-4.

Congratulations again to Mr. Ojha and Dr. Sehitoglu for winning this prestigious award!

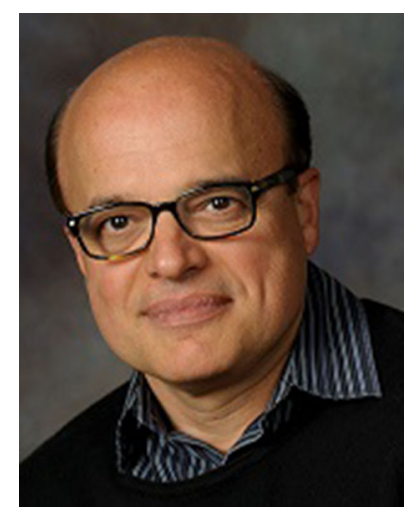

Dr. Huseyin Sehitoglu, Nyquist Chair, University of Illinois at Urbana-Chamagn 